Article

\title{
Hydraulic Performance of Lined Permeable Pavement Systems in the Built Environment
}

\author{
Jan Støvring * (iD), Torben Dam and Marina Bergen Jensen \\ Department of Geosciences and Natural Resource Management, University of Copenhagen, \\ DK-1958 Frederiksberg, Denmark; toda@ign.ku.dk (T.D.); mbj@ign.ku.dk (M.B.J.) \\ * Correspondence: jls@ign.ku.dk; Tel.: +45-3533-1837
}

Received: 29 November 2017; Accepted: 23 April 2018; Published: 1 May 2018

check for updates

\begin{abstract}
The hydraulic performance of permeable pavement (PP) systems has been well demonstrated when based on full or partial on-site infiltration, while there is only limited research on lined PP systems built to provide detention and volume reduction by evaporation only. In this study, we tested the performance of commercially available PP components when constructed as lined PP systems with un-throttled discharge to explore basic hydraulic function in a real-life-setting. Four types of PP surface products and three types of sub-base aggregates were tested in six unique combinations, built as side-by-side parking lots into an existing parking area, each stall having a size of $25 \mathrm{~m}^{2}$ and $0.5 \mathrm{~m}$ of depth with individual lining. Based on 12 months of monitoring precipitation and discharge from each stall, total volume reduction ranged from $3 \%$ to $37 \%$. Analysis of up to 22 single events, representing return periods of up to two years, revealed marked detention capacities, expressed as median volume reduction of $40 \%$, spanning $27-69 \%$ and median lag time of 1:38 h, spanning 0:39-3:16 h, across all stalls. The considerable range in hydraulic properties can be ascribed to both surface and sub-base properties.
\end{abstract}

Keywords: climate adaptation; detention; retention; SCM; storage capacity; storm water; SUDS

\section{Introduction}

Permeable pavement (PP) systems provide on-site storm water management that is useful not only as a way to provide a well-drained pavement, independent of conventional pipe-based drainage systems, but also as a means to reassert ecological balances of urbanized catchments while adapting cities to heavier downpours due to changing climate. As such, PP systems are an embedded part of sustainable urban drainage system (SUDS) and Green infrastructure (GI) storm water control measures (SCMs) [1,2]. In urbanized catchments, however, the environmental concern related to contaminants as well as shallow groundwater or risk of water ingress in nearby buildings limits the uptake of PP systems and in such cases, a lined PP system may be durable, as the use of a watertight geo-membrane helps meet these concerns [2]. While wrapping a geo-membrane around the below surface perimeter disables on-site infiltration, a lined PP system will still provide storage capacity, volume reduction by way of evaporation, and detain intense rain storms, eventually reducing the risk of pluvial flooding and combined sewer overflow (CSO) [1]. Furthermore, on an annual basis, the volume reduction caused by evaporation from the PP system may affect the overall urban water balance by reducing the volume discharged from the city, thus reducing the volume that needs treatment in the combined sewer system. Lined PP systems are comparable to underground detention installations, but deviate in their evaporation potential and may also display a slower drainage pattern if capillary forces are active in the subbase aggregates.

With a focus on PP systems as a means to promote on-site infiltration, the hydraulic function of non-lined PP systems is well described [3-9], while fewer studies document the function of 
lined PP systems in a real-life setting. Recent studies conducted at a parking area retrofitted in 2009 at the USEPA's (U. S. Environmental Protection Agency) Environmental Center, Edison, New Jersey [10], and in 2011 at Washington State University's Research and Extension Center in Puyallup, Washington [11], both in the US, represent state of knowledge on lined PP systems along with earlier studies conducted at Clifton Campus, Tent Polytechnic at a parking lot built in 1986 [12,13] and at a parking area near Oxford built in 1998 [14], both in the UK. The studies have documented performance criteria regarding storage capacity, accumulated water balances as well as water balance of single events as further detailed below.

Pratt et al. $[12,13]$ studied the storage capacity four types of lined PP systems built as side-by-side parking lots, each $46 \mathrm{~m}^{2}$ in size and separated from each other by an impermeable membrane, paved with almost identical PP surface layer but different sub-base aggregates. A considerable span in sub-base porosities were observed, with 31\% for $10 \mathrm{~mm}$ round gravel, $42 \%$ for $5-40 \mathrm{~mm}$ (crushed) granite, $43 \%$ for 5-40 mm carboniferous limestone, and $48 \%$ for $40 \mathrm{~mm}$ blast furnace slag [13]. The span in porosities is associated with the individual shape and gradation of the material as well as degree of compaction, where aggregates of uniform particle size and angular shape represent the highest porosity [15]. According to Ferguson [16], internal pores in aggregates can enhance the porosity, which is normally found within the range of 30 to $40 \%$. Laboratory tests conducted by Park et al. [17] on aggregates for sub-base use in PP systems found porosity to be $29 \%$. Relating those studies to aggregates studied by Pratt et al. [13] highlights well-performing sub-base materials in terms of the storage capacity provided.

Brown and Borst [10] studied three types of PP system surfaces on top of a $400 \mathrm{~mm}$ thick subbase of recycled concrete aggregates (RCA) that were crushed and screened on site to the size of 50-63 mm, covering a parking area of $4000 \mathrm{~m}^{2}$. Permeable asphalt (PA) and Portland cement pervious concreate (PCPC) were constructed directly on the sub-base, while permeable interlocking concrete pavement (PICP) was installed on a bedding layer of $12.5 \mathrm{~mm}$ aggregates and a choking layer of $25 \mathrm{~mm}$ aggregates overlaying RCA. For three types of PP system surfaces, each divided into four separately enclosed sections, cumulative precipitation and subsurface discharge were monitored for almost two years, resulting in mean cumulative evaporation of $5.2 \%$ of precipitation, spanning from $2.4-7.6 \%$ in the order PCPC > PICP > PA. Since the PP systems tested received runoff from adjacent impermeable pavement, annual evaporation rates were converted to account for direct rainfall only, resulting in values of $12 \%$, $8 \%$, and 7\% for PCPC, PICP and PA surfaces, respectively. Interestingly, evaporation for dark PA is less than for the two light gray PP surfaces tested pointing towards a diminutive albedo effect. In the same study, the average daily evaporation rate was estimated to be $1.37 \mathrm{~mm}$ (ranging from 0.87 to $1.81 \mathrm{~mm}$ across PP systems and replicates), while Pratt et al. [13] found evaporation to be some $0.2 \mathrm{~mm}$ daily during dry weather periods, but as high as $5.5 \mathrm{~mm}$ per day during wet weather periods monitored by use of a $0.5 \mathrm{~m}^{2}$ model of the experimental set-up, placed next to the field test site. The above mentioned full-scale studies are supplemented by quasi-experiments (outdoor PP systems not subjected to usage) conducted by Göbel et al. [18], in which evaporation ranged 10-18\% for pervious concrete measured from August to October (warm months), with surface color in anthracite color (dark) returning 19\% higher evaporation relative to the same paver in light grey. Furthermore, it was found that PP systems designed with a two-layered sub-base with a shift in aggregate size provided $16 \%$ less evaporation, possibly ascribed to capillary breakage between finer aggregates overlaying a coarser layer [19]. Li et al. [20] exposed samples of PA, PCPC and three types of aggregates (size 9.5, 12.5 and $19 \mathrm{~mm}$ ) to natural weather conditions during three warm days $\left(36-39{ }^{\circ} \mathrm{C}\right)$ and found that sand $(<9.5 \mathrm{~mm}$ particles) under the influence of capillary forces provided the highest evaporation rate of $1.8 \mathrm{~mm} / \mathrm{h}$, equivalent to $70 \%$ of evaporation from open water. However, the study found a positive correlation between evaporation, void share in surface material and permeability for all other materials tested and thus suggests that evaporation from a PP system is under the influence of both capillarity and porosity. The influence of both the PP system sub-base aggregates and surface material on the water balance as well as attenuation has further been investigated by Jorge et al. [21] in which PICP and PA 
and sub-base aggregates of recycled Construction and Demolition debris (C\&D aggregates) and well as limestone were studied in combinations by way of 32 simulated rainfalls. Specimens with $C \& D$ aggregates returned the highest volume reduction and lag-time that was especially pronounced in combination with PA.

At the parking lots studied by Pratt et al. [12,13], 42 out of 62 events resulted in measurable discharge $(>0.25 \mathrm{~mm} / \mathrm{h})$ with a mean discharge of $37 \%$ for PICP on a sub-base of rounded gravel, $47 \%$ for granite aggregates, $45 \%$ for carboniferous limestone and $34 \%$ for blast furnace relative to precipitation, and with the first occurrence of discharge always $25-50 \%$ into the rain duration. No measurable discharge was observed for rainfall smaller than $5 \mathrm{~mm}$ [13]. In [14], the performance of porous blocks built on a sub-base of crushed gravel, rock, and crushed concrete found lag time up to $2: 00 \mathrm{~h}$ and mean volume reduction of $22.5 \%$ when monitored over the course of 13 months (rain depths 3.0-20.6 mm). Knappenberger et al. [11] constructed a parking area paved with $3200 \mathrm{~m}^{2} \mathrm{PA}$ divided into nine individual lined and monitored stalls, including one control with conventional impermeable asphalt and found mean lag-time for PA to be 2-3 h, depending on maintenance regime while run-off from the control resulted in a mean lag-time of 0:54 h based on analysis of nine distinct events. Surprisingly, the highest lag-time was experienced for the unmaintained PA, which leads to the conclusion that small particles in the deeper part of the asphalt structure caused by the applied maintenance technique affect the lag-time.

Although the concept of PP systems is not new, knowledge about their performance requires further qualification since various factors influence performance: specific PP system design and climatic conditions along with other contextual factors, as well as knowledge on PP system components currently available on the commercial market is a research need [8]. This should be done as enclosed or lined PP systems built in a real-life-setting to derive estimates on storage capacity, annual water balance as well as for single events and lag time. Accordingly, the research objectives in this study were:

- to determine storage capacity of a selection of sub-base aggregates;

- to document surface permeability of a range of PP systems;

- to estimate total volume reductions over a significant observation period; and

- to estimate volume reductions and lag time for single events.

\section{Materials and Methods}

As parking areas are often mentioned as ideal for PP systems [1], an existing public parking area was chosen for constructing six unique and individual lined and monitored PP systems. The six experimental stalls were equally sized of $25 \mathrm{~m}^{2}$, corresponding to two parking lots and situated next to each other at the most frequently used area at a parking lot next to a public sport facility in Copenhagen, Denmark ( $\left.55^{\circ} 42^{\prime} 51^{\prime \prime} \mathrm{N}, 12^{\circ} 34^{\prime} 42^{\prime \prime} \mathrm{E}\right)$. The sports facility has long opening hours all weekdays and all year round except for a summer break; thus, the parking lots were intensively used. By placing a raised concrete tile along the perimeter of each stall, a $20 \mathrm{~mm}$ high boundary towards the surroundings was formed, ensuring that only rainfall over the individual stall was captured and infiltrated. The stalls were fitted to existing terrain conditions, resulting in a cross fall of $1.5 \%$. The bottom of each of the stalls was individually lined with a $2 \mathrm{~mm}$ polyethylene (HDPE) membrane overlaid with a studded membrane of polypropylene $(12 \mathrm{~mm}$ ) (Platon) to prevent the underlying membrane from being perforated as sub-base aggregates were built in. Tightness tests were conducted by allowing water to stand for $12 \mathrm{~h}$, after the first half of aggregates were in place and compacted as membrane rupture has previously been reported as a possible source of error in interpreting data [10,11]. The HDPE membrane was folded in corners to also cover sides, and finally, pinched between surface layer and the circumscribing tile. To ensure free discharge, a $110 \mathrm{~mm}$ diameter perforated pipe was placed on the studded membrane downstream and connected to a $600 \mathrm{~mm}$ monitoring well placed outside the PP system, through a sealed socket perforation of the membrane. From the monitoring well, discharge was pumped by way of a submerged pump to the piped drainage network. Stalls $1-5$ had a reinforcement 
net directly on top of the studded membrane, as well as at a level of $300 \mathrm{~mm}$ below pavement surface to minimize the risk of deformations. Plan and cross-section illustrations of the six stalls are presented in Figure 1.

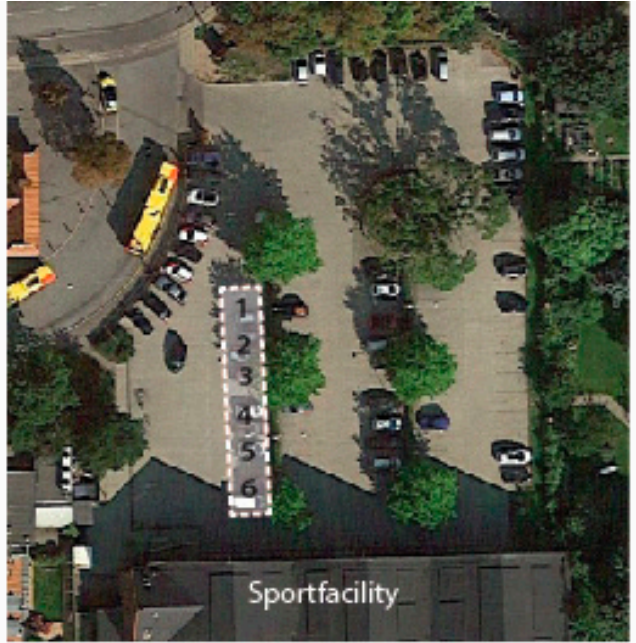

(a)

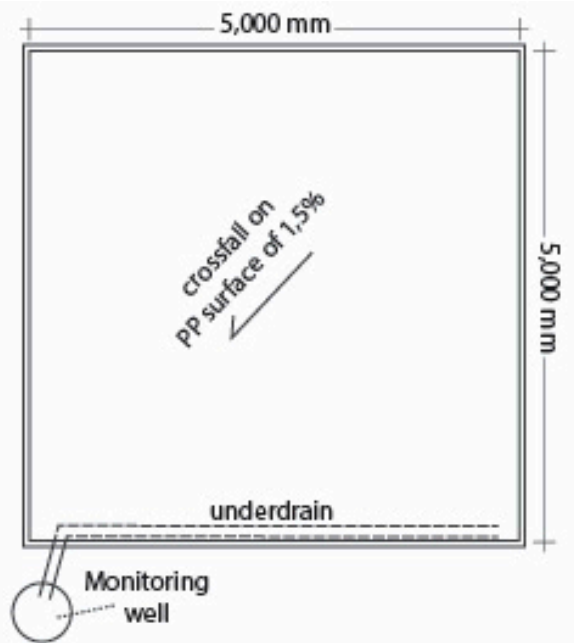

(b)

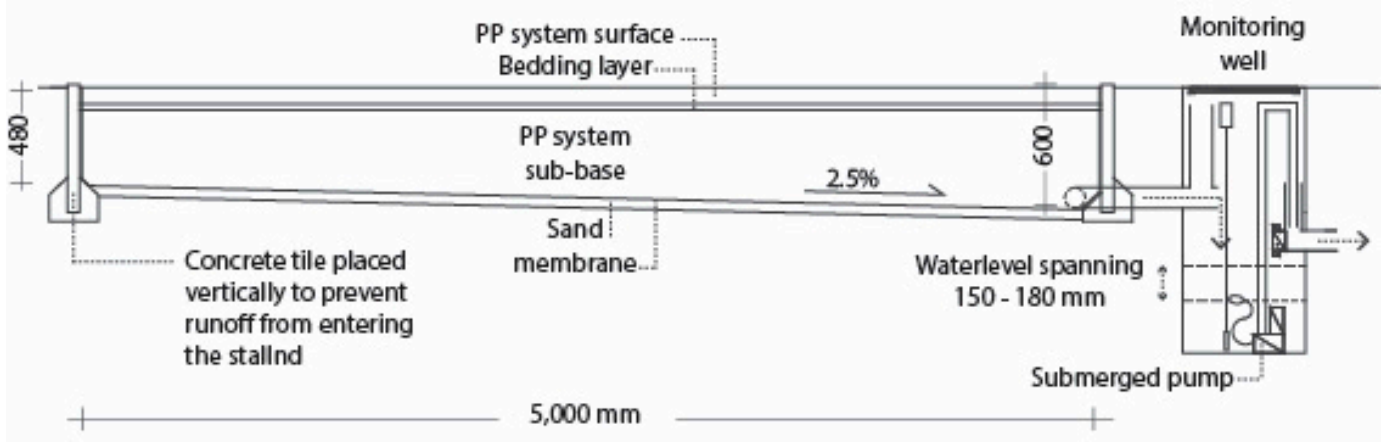

(c)

Figure 1. Location and construction of the six experimental stalls of lined PP-systems with: (a) an aerial photo of the parking area with position of stalls marked; (b) diagram of an individual stall; and (c) a cross-section of individual stall and monitoring well.

Each of the experimental stalls was constructed with a sub-base layer, a surface layer as well as a bedding layer if required, selected to test commercially available products resulting in six unique combinations (Figure 2).

Stalls were built during the early months of 2013 and put into use in the beginning of May 2013. Due to a number of malfunctions related to local power outage, software problems and defective instruments, we report a continuous monitoring period of 12 months starting from 1 December 2014, i.e., to a starting point 19 months after completion of installation, thus initial high surface permeability rates were assumed to have settled to a more permanent level $[9,22,23]$, providing results representative of a longer period of functional lifetime. The stalls were enrolled in the present maintenance program for surrounding conventional pavements, which includes occasional collection of litter and debris, but no specific actions to maintain high surface permeability. 


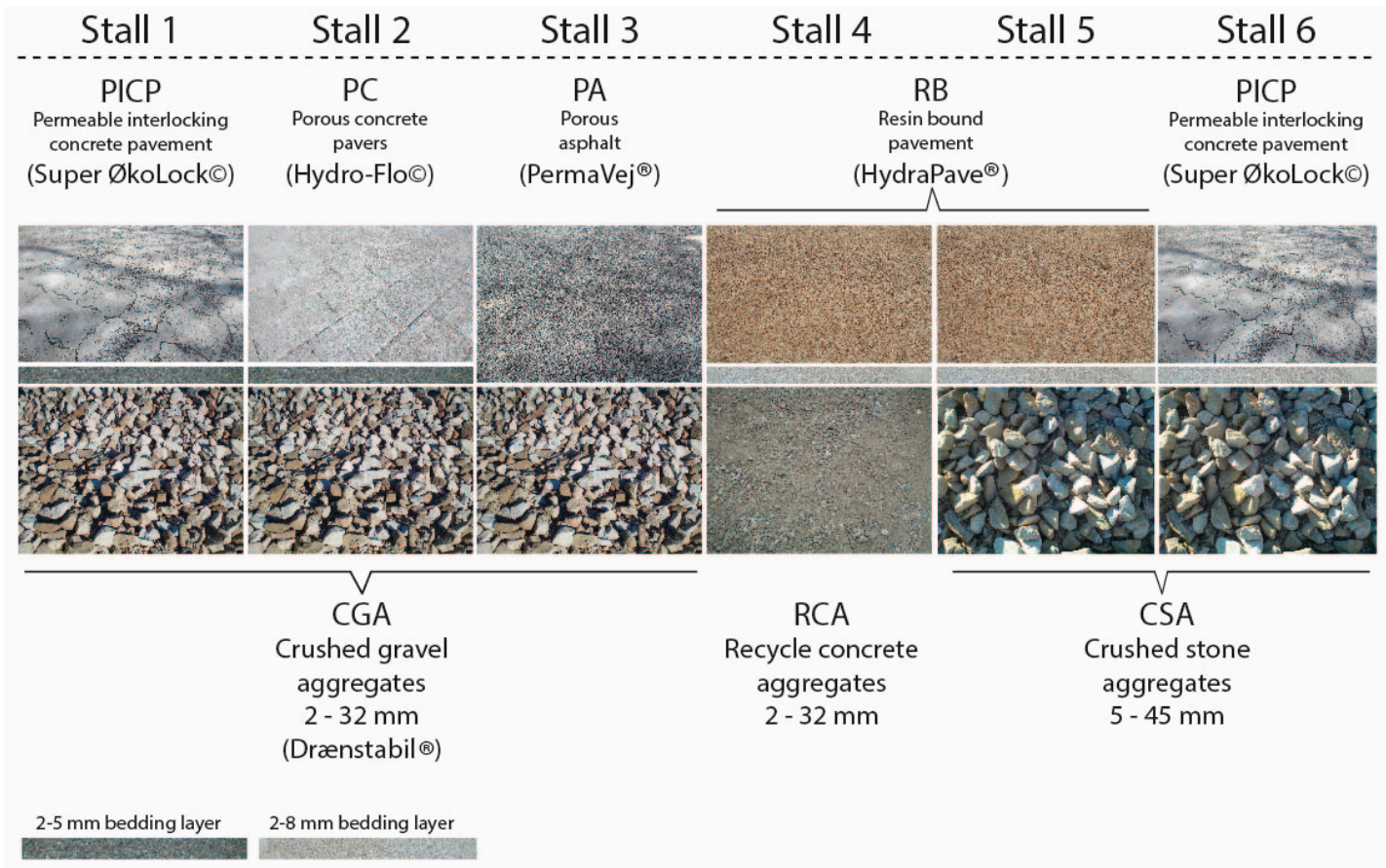

Figure 2. Diagram showing the combination of surface layer, bedding layer and sub-base layer of PP systems tested in six stalls, including photos of individual layer materials, where CGA = crushed gravel aggregates; $\mathrm{RCA}=$ recycled concrete aggregates; and CSA = crushed stone aggregates.

\subsection{PP Sub-Base Layers}

Aggregates for the sub-base layer of $400-520 \mathrm{~mm}$ thickness were selected to represent different granular materials including:

- Crushed gravel aggregate (CGA), Drænstabil ${ }^{\circledR}$ (NCC Råstoffer A/S), specified range 2-32 mm;

- Recycled concrete (RCA), (Norocco A/S), specified range 2-32 mm; and

- Crushed stone aggregate (CGA), (Stenrand), specified with $80 \%$ in range $25-45 \mathrm{~mm}$ and $20 \%$ in range $5-8 \mathrm{~mm}$, added to minimize internal downwards migration of aggregates.

Specific attention was paid to avoid the use of particles less than $2 \mathrm{~mm}$. The sub-base materials were mixed by the supplier and delivered unwashed and applied to the site according to suppliers' specifications. During construction, samples of materials were collected at the construction site for control of gradation by laboratory measurement of particle size distribution according to DS/EN 993-1 and calculation of coefficient of uniformity $\left(C_{u}\right)$ expressed as $D_{60} / D_{10}$, where $D$ is the sieve size to a specific percentage of particles passing that sieve (by weight). The coefficient of uniformity was calculated to give a characteristic of the grading profile, where $C_{u}$ in the range of 2.0-2.5 characterizes an open-graded distribution, while a higher value characterizes a more dense-graded distribution [16].

\subsection{PP Surfaces and Bedding Layers}

Together with a city officer from Copenhagen Municipality, four types of commercially available PP surface products in different colors and textures were chosen for testing, thus representing a variety in terms of aesthetics, functionality, and infiltration concepts likely to be taken into use in the City of Copenhagen. The types of PP surfaces include:

- $\quad$ Permeable interlocking concrete pavement (PICP), type Super ØkoLock ${ }^{\odot}$ (Ikast Betonvare Fabrik, Ikast, Denmark), $80 \mathrm{~mm}$ thick, permeable openings $50 \mathrm{~mm}$ by $50 \mathrm{~mm}$ representing a total void share of $10 \%$ at the surface; 
- Porous concrete pavers (PC), type Hydro-Flo ${ }^{\odot}$ (Midtgaard A/S, Roskilde, Denmark), $130 \mathrm{~mm} \times 210 \mathrm{~mm}$ and $70 \mathrm{~mm}$ thick, and porosity of $7 \%$ stated by supplier;

- Resin bound pavement (RB), type HydraPave ${ }^{\circledR}$ (Byggros, Odense, Denmark), 45 mm thick, and porosity of $30-40 \%$ stated by supplier; and

- $\quad$ Porous asphalt (PA), type PermaVej ${ }^{\circledR}$ (NCC Roads, Søborg, Denmark), $40 \mathrm{~mm}$ thick base-layer with porosity of $14.8-16.1 \%$, and $60 \mathrm{~mm}$ thick top-layer with total porosity of $19.8-24 \%$.

Thus, the experiment represented PP systems with permeable joints (PICP), permeable pavers (PC), and permeable monolithic structures (RB and PA). Regarding PICP, the permeable openings were filled with 2-5 mm aggregates, while the 1-2 mm conventional joints in the PC were filled with 1-2 mm aggregates. For PICP and PC, a $30 \mathrm{~mm}$ thick bedding layer of $2-5 \mathrm{~mm}$ aggregates was used. The RB was mixed on-site using crushed stone $1-3 \mathrm{~mm}$ aggregate size and placed on a $30 \mathrm{~mm}$ bedding layer of 2-8 $\mathrm{mm}$ aggregates. PA was applied directly on the sub-base in a two-step process resulting in a base-layer and a top-layer, and afterwards three core samples were subsequently examined by the supplier to measure the void share. Since small manual equipment was used for construction of the PA, some unevenness in distribution of voids was expected.

\subsection{Monitoring and Data Analysis}

Storage capacity (SC) of aggregates was empirically determined in the laboratory by use of boxes with a volume, $V_{b o x}$, of $48 \mathrm{~L}$, measuring $610 \mathrm{~mm} \times 315 \mathrm{~mm}$ and $402 \mathrm{~mm}$ in height (two replicates). To account for surface moisture on the individual aggregates as well as moisture in internal pores of aggregates, the storage capacity of dry aggregates $\left(S C_{d r y}\right)$ as well as moist (after soaking and drainage for $24 \mathrm{~h}$ ) sub-base aggregates $\left(S C_{\text {moist }}\right.$ ) was determined. The former is seen as an optimistic estimate for $\mathrm{SC}$ and the latter more realistic with respect to the capacity when constructed in a real-life setting, where aggregates will rarely dry up completely. Samples of dry aggregates were collected at the construction site and manually packed in boxes, filling the box to the rim and carefully compacting after each $100 \mathrm{~mm}$ using a sledgehammer, to finally form an even surface. Then, the boxes were weighed, returning the weight of dry aggregates, $M_{\text {dry aggregates }}$ (after subtracting of weight of empty box), filled with water, and weighed again returning the weight of aggregates and water, $M_{\text {aggregates }}+$ water (after subtracting of weight of empty box), allowing us to calculate $S C_{d r y}$, using Equation (1).

$$
S C_{d r y}=\frac{M_{\text {aggregates }+ \text { water }}-M_{\text {dry aggregates }}}{V_{\text {box }}} \times 100
$$

Afterwards, the box was drained for $24 \mathrm{~h}$ by opening a valve in the bottom of the box, and weighed,

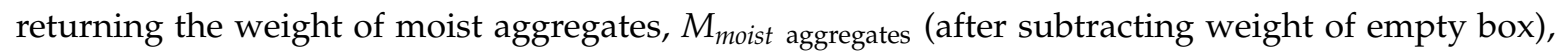
allowing us to calculate storage capacity of moist aggregates, $S C_{\text {moist }}$, using Equation (2):

$$
S C_{\text {moist }}=\frac{M_{\text {aggregates }+ \text { water }}-M_{\text {moist }}}{V_{\text {box }}} \times 100
$$

Each of the six monitoring wells serving the six stalls was equipped with a pressure transducer (MJK Expert ${ }^{\mathrm{TM}} 7060$ hydrostatic level-transmitter from MJK) to allow for high resolution data of discharge volumes. The equipment is similar to equipment used by, e.g., Drake [7] and Brown and Borst [10]. The precision was $\pm 2 \mathrm{~mm}$ and subsurface discharge volumes were logged using an interval of $1 \mathrm{~min}$. Discharge was thus allowed to raise temporarily in the monitoring well before being rapidly pumped to the existing combined sewage system using a submerged pump adjusted to start when water level reached a fixed level (Figure 1). Pumping always started within an interval of 150-180 mm water depth in the well (diameter of $600 \mathrm{~mm}$ ), which corresponds to the pumping of 42.4-56.5 L equivalent to a maximum of $1.70-2.26 \mathrm{~mm}$ of rain depth that may not be counted in the final pumping session of each event, should $100 \%$ of rainfall reach the well. All pumping sequences were identified in the post data analysis, and corrupted data during time of pumping (1-3 $\mathrm{min}$ ) was compensated by 
using an average value of the preceding $3 \mathrm{~min}$ data value. To calculate discharge, a depth to volume relationship was developed accumulating discharge minute by minute. For analysis, data were bulked in 10-min intervals.

Precipitation was monitored by use of a tipping-bucket rain gauge with a resolution of $0.2 \mathrm{~mm}$. The rain gauge was placed at a height of $4 \mathrm{~m}$ next to the experimental stalls. Data were logged ("Chatter", MJK), connected by telemetry to a server at the University of Copenhagen.

Every six months, surface infiltration tests in triplicates were conducted at each stall following ASTM C1781/C1781M-13 [24]. This was to verify that no surface runoff was generated from any of the stalls.

Total volume reduction $\left(V R_{\text {total }}\right)$ over the observation period (12 months) was calculated for each stall as fraction of accumulated precipitation $\left(V_{\text {precipitation }}\right)$ not discharged $\left(V_{\text {discharge }}\right)$, using Equation (3). Volume reduction is assumed to represent evaporation loss.

$$
V R_{\text {total }}=\frac{V_{\text {precipitation }}-V_{\text {discharge }}}{V_{\text {precipitation }}} \times 100,
$$

The assessment of hydraulic performance of single events was based on analysis of events resulting in discharge identifiable from a base flow not exceeding $0.3 \mathrm{~mm} / \mathrm{h}$ at the beginning of the event, and where no new event would start before reaching the same low level of base flow. Since the PP systems produced discharge for hours and sometimes days, choosing the discharge cut-off was a matter of being able to single out individual events in a climate with frequent recurring events, found more important than choosing a certain low base flow. The cut-off level is similar to $0.25 \mathrm{~mm} / \mathrm{h}$ as used by Pratt et al. [13]. Further, to obtain comparable results across stalls, no less than four stalls should produce discharge. Performance assessment included VR on event-basis, using Equation (4), and lag time $\left(t_{\text {lag }}\right)(\mathrm{hh}: \mathrm{mm})$ calculated on a volume-basis as the center of mass (centroid lag) defined as the time between the centroids of precipitation $\left(t_{\text {precipitation }}\right)$ and discharge $\left.\left(t_{\text {stall }}\right)\right)$ [25], using Equation (5):

$$
\begin{gathered}
V R_{\text {event }}=\frac{V_{\text {precipitation event }}-V_{\text {stall event }}}{V_{\text {precipitation event }}} \times 100, \\
t_{\text {lag }}=t_{\text {stall }}-t_{\text {precipitation }}
\end{gathered}
$$

\section{Results and Discussion}

\subsection{Storage Capacity}

The results of particle size distribution for the different sub-base aggregates and their uniformity coefficient are shown in Figure 3. For CGA, the coefficient of uniformity and particle size distribution reflect a coarse-graded material, although with $10 \%$ of mass less than $2 \mathrm{~mm}$ of size. For RCA, aggregates less than $2 \mathrm{~mm}$ of size made up $12 \%$, and the coefficient of uniformity as well as particle size distribution reflect a more densely coarse-graded material when compared with the CGA. Analysis of particle distribution showed $0.7 \%$ of mass with a size less than $2 \mathrm{~mm}$ and only $13 \%$ of aggregates were found to be less than $8 \mathrm{~mm}$. Coefficient of uniformity show CSA to be the most open-graded sub-base type, reflecting the presence of large- and medium-sized aggregates. CSA can be characterized as a gap-graded material due to the high percentage of material found in two sieve intervals with little or no mass in-between. In general, the presence of particles less than $2 \mathrm{~mm}$ in all samples can be attributed to stone dust since none of the aggregates were washed before use, and for RCA, furthermore, that aggregates based on recycled concrete can easily be crushed during transportation and on-site management [26].

Laboratory measurements of sub-base materials showed diminutive differences in storage capacity among dry aggregates, $S C_{\text {dry aggregates, }}$, ranging from $34.4 \%$ to $36.2 \%$, but considerable differences when considering moist aggregates, $S C_{\text {moist }}$, that were found within a range of $27.5 \%$ to $35.3 \%$ (Table 1 ). 


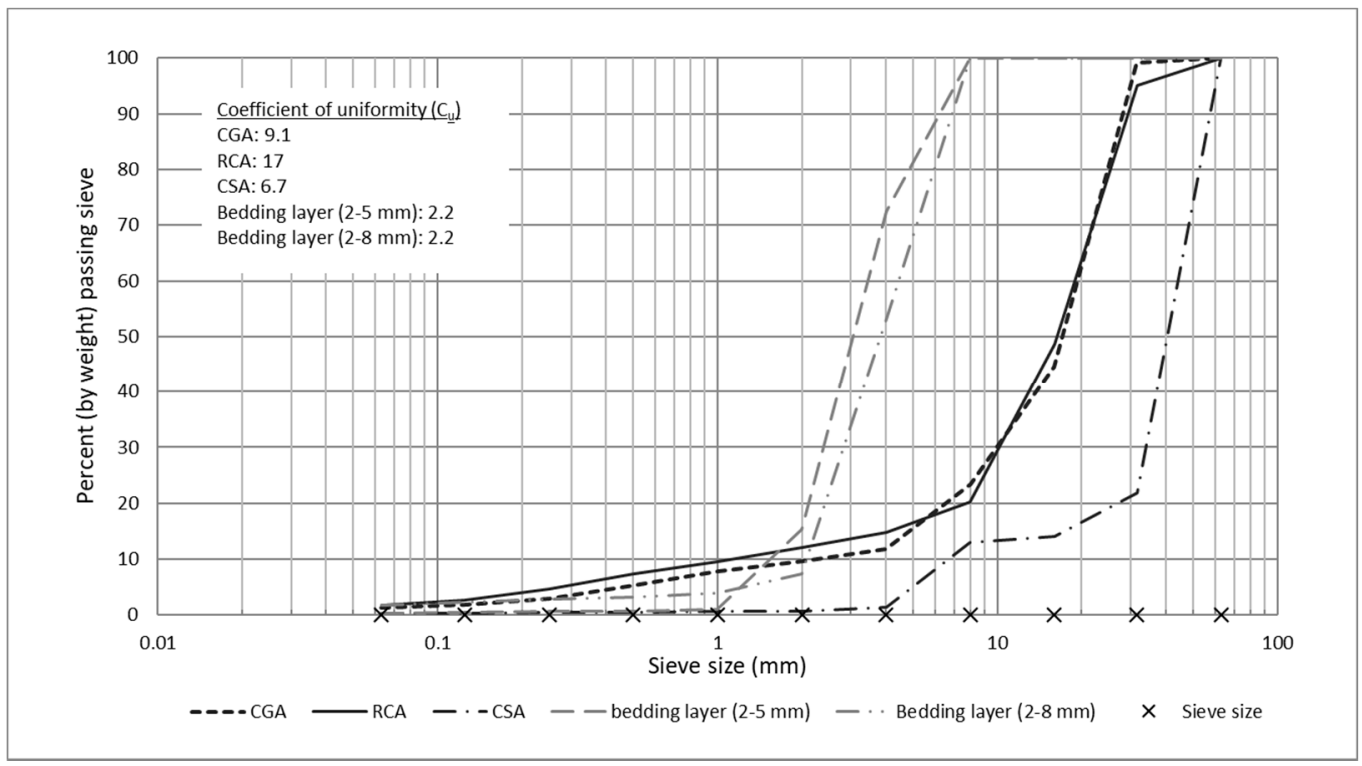

Figure 3. Particle size distribution of sub-base aggregates used in the six stalls and their coefficients of uniformity $\left(\mathrm{C}_{\mathrm{u}}\right)$. CGA = crushed gravel aggregates; $\mathrm{RCA}$ = recycled concrete aggregates; and CSA $=$ crushed stone aggregates. The sieves ranging from 0.063 to $63 \mathrm{~mm}$ according to DS/EN 993-1 are marked with an $\mathrm{X}$ on the horizontal axis.

Table 1. Storage capacities of sub-base aggregates used in the test. CGA = crushed gravel aggregates; $\mathrm{RCA}=$ recycled concrete aggregates; and CSA = crushed stone aggregates.

\begin{tabular}{cccc}
\hline Storage Capacities & CGA & RCA & CSA \\
\hline$S C_{d r y}$ & $34.4 \%$ & $36.4 \%$ & $36.2 \%$ \\
$S C_{\text {moist }}$ & $30.8 \%$ & $27.5 \%$ & $35.3 \%$ \\
\hline
\end{tabular}

The reduction in storage capacity from dry to moist indicates that the more open-graded aggregate (CSA) drains more of the stored water due to the absence of the capillary forces, resulting in SC of moist materials being close to that of dry materials. In line with this, it was observed during tests dry RCA containing the highest fraction of fine material showed the biggest reduction of $8.9 \%$ between $S C_{d r y}$ and $S C_{\text {moist }}$, a value similar to the $9.4 \%$ difference found by Jorge et al. [21] on C\&D aggregates. However, the level of storage capacities found in this study are in the lower range of what could be expected according to Shergold [15] and Ferguson [16]. This probably reflects the greater $C_{u}$ of the real-life materials (Figure 3) than normally accounted for in open-graded sub-base aggregates, where $\mathrm{C}_{\mathrm{u}}$ is often below 2 [16]. This could also be the reason for the storage capacity found in this study being less than what was found in three of four materials tested by Prat et al. [12,13]. These rather significant differences stress the importance of careful specification as well as on-site management of aggregates to be used in PP systems.

\subsection{Surface Permeability}

The results of on-site tests of permeability documented that all six stalls remained within their initial range throughout the experiment, confirming that initial drops in SIR had largely settled (Table 2). A great variety among stalls was observed as well as some decrease over the course of the observation period, except for Stalls 2 and 6 where SIR (partly) increased. However, as the surface infiltration test was conducted at Stall 2, a marked decrease in SIR from the first to the second of the three tests prescribed was experienced, e.g., from $7 \mathrm{~min}$ to $60 \mathrm{~min}$. The authors hypothesize that active capillary forces and a hydraulic barrier between paver and bedding-layer affects the SIR measured by way 
of the ASTM C1781/C1781M-13 procedure and thus SIR listed in Table 2 might underestimate the ability to capture rainfall for stall 2. Because no rain event intensities monitored during the period exceeded measured SIR, not even for Stall 3 despite low surface permeability, it is concluded that all direct rainfall during the monitoring period was managed within each stall.

Table 2. Surface infiltration rates (SIR) of the six stalls during monitoring period.

\begin{tabular}{ccccccc}
\hline Time of Test & $\begin{array}{c}\text { Stall 1 } \\
(\mathbf{m m} / \mathbf{h})\end{array}$ & $\begin{array}{c}\text { Stall 2 } \\
\mathbf{( m m / h )}\end{array}$ & $\begin{array}{c}\text { Stall 3 } \\
\mathbf{( m m / h )}\end{array}$ & $\begin{array}{c}\text { Stall 4 } \\
\mathbf{( m m} / \mathbf{h})\end{array}$ & $\begin{array}{c}\text { Stall 5 } \\
\mathbf{( m m / h )}\end{array}$ & $\begin{array}{c}\text { Stall 6 } \\
\mathbf{( m m} / \mathbf{h})\end{array}$ \\
\hline Fall 2014 & 877 & 46 & 24 & 16,750 & 18,519 & 444 \\
Spring 2015 & 775 & 145 & 17 & 9555 & 9880 & 568 \\
Fall 2015 & 398 & 140 & 16 & 7759 & 5944 & 699 \\
\hline
\end{tabular}

\subsection{Total Volume Reduction $\left(V R_{\text {total }}\right)$}

A total precipitation of $756 \mathrm{~mm}$ was registered over the course of the monitoring period of 365 days with a mean temperature of $9.4^{\circ} \mathrm{C}\left(-9.9-31.6^{\circ} \mathrm{C}\right)$ and only 34 days with frost, which made the period wetter and warmer than normal [27]. Calculating $\mathrm{VR}_{\text {total }}$ for all six stalls returned a mean discharge of $649 \mathrm{~mm}$ resulting in a mean $\mathrm{VR}_{\text {total }}$ of $16 \%$ (corresponding to $107 \mathrm{~mm} / \mathrm{yr}$.), and covering a range from 3\% (23 mm/yr.) for Stall 1 to $37 \%(280 \mathrm{~mm} / \mathrm{yr}$.) for Stall 3 (Figure 4). The volume reduction is assumed to be caused by evaporation. The mean evaporation rate is slightly higher than evaporation from soil in natural areas with high oak ( $77 \mathrm{~mm} / \mathrm{yr}$.) as well as from low heath vegetation $(95 \mathrm{~mm} / \mathrm{yr}$.) found under similar climatic conditions, while the high evaporation rate found at Stall 4 is around half the evapotranspiration from land covered with high oak $(515 \mathrm{~mm} / \mathrm{yr})$ [28]. This indicates that evaporation rates of PICP, PC and RB with sub-base of coarse aggregates $\left(C_{u}=6.7-9.1\right)$ are comparable to evaporation rates from soil, however, covered with a natural vegetation, while PA on same type of sub-base aggregates are even higher. The fact that the two highest VRs are found for the monolithic permeable structures of RB and PA above subbase aggregates with highest content of fine materials could indicate an interesting combination of surface and subbase materials allowing for unbroken capillary transport of water allowing for evaporation to continue for a long period after rain.

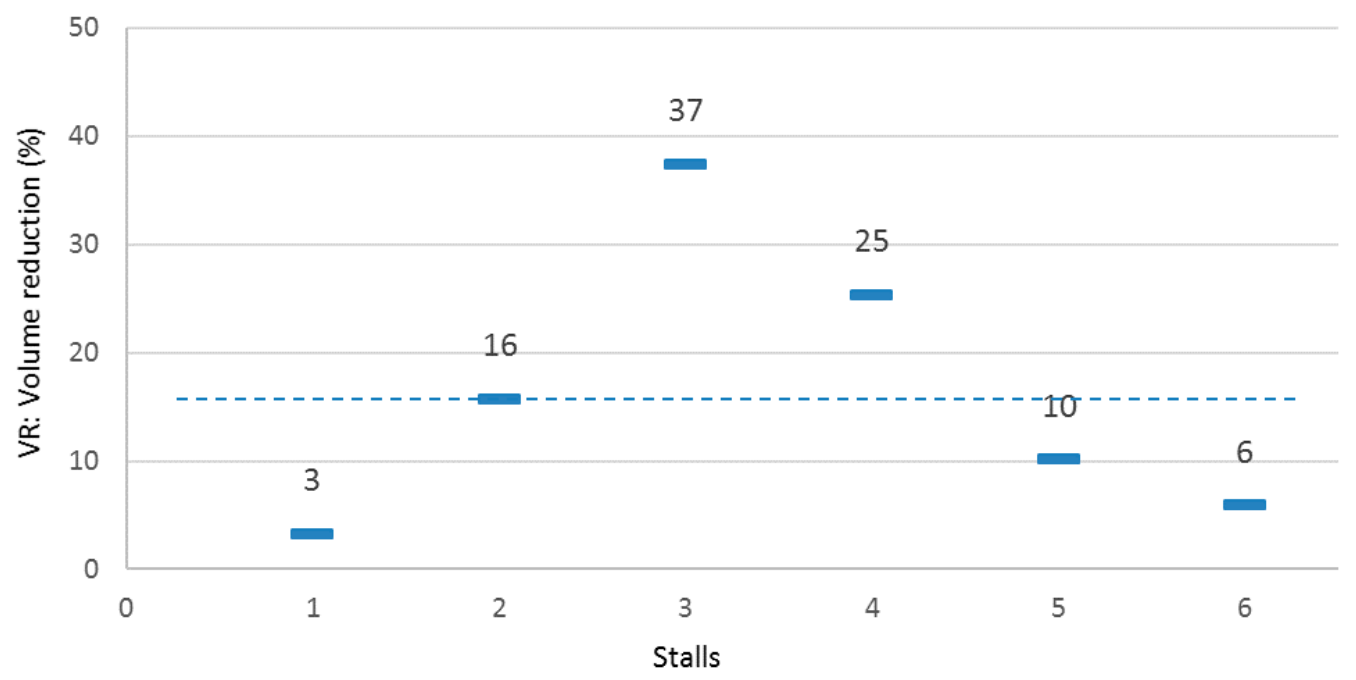

Figure 4. Total volume reduction $\left(V R_{\text {total }}\right)$ for each of six stalls over a period of 12 months. Mean volume reduction across all stalls shown as dashed line.

Stalls $1-3$, which were all built with CGA as sub-base, resulted in $V R_{\text {total }}$ of $3 \%$ for PICP, $16 \%$ for PC, and 37\% for PA, and Stalls 5 and 6, which were both built with CSA as sub-base, resulted in $V R_{\text {total }}$ of $10 \%$ for RB and $6 \%$ for PICP. Difference in $V R_{\text {total }}$ within each of the two groups of stalls are 
attributed the specific PP surface properties, since all other variables are the same, although under the influence of the specific sub-base aggregates. We expect total residence time in the top of the PP system to allow for larger evaporation losses and an indirect measure for this is the surface infiltration rate (SIR), that was measured on-site during the monitoring period (Table 2). Results from Stalls 1-3 indicate a correlation based on SIR, however, this is not the case for Stalls 5 and 6. Due to the research design, in which no repetitions were included and PP system combinations of surface and sub-base designs were only partly overlapping, we are cautious in our interpretation of the results. However, previous lab-based studies suggest that the smaller void-share in the PICP might accelerate the development of preferential paths within the sub-base resulting in lower $V R_{\text {total }}$ when compared to the monolithic surfaces with a greater drainage area [21]. The greater $V R_{\text {total }}$ found for PC might be the result of a hydraulic barrier between the paver and the bedding layer in which the water remains in the fine pores of the paver until the pressure head builds up large enough for the water to enter the larger pores in the more coarse sub-base material [19]. The observations from conducting the surface infiltration tests supports that the effect of a hydraulic barrier can be notable. The same hydraulic mechanisms can (partly) explain the high $V R_{\text {total }}$ for PA, however we expect the effect to be smaller due to the higher void-share, compared to PC. It is also possible that the dark surface color affects evaporation with an effect of close to a $20 \%$ increase when compared to grey surfaces [18], while others have estimated no effect due to color in the case of a frequent used parking area [10]. Difference in $V R_{\text {total }}$ found for RB and PICP is rather small, however, RB returned the highest $V R_{\text {total }}$ which we find counter-intuitive when taking the SIR measurements into consideration as well as the fact that RB is a monolithic structure with high porosity. Part of the $4 \%$ difference could be caused by monitoring uncertainty as well as differences in precipitation input due to the greater building just south of the experimental stalls or the fact that Stall 6 (paved with PICP) is situated slightly more in the shadow of the same building, thus allowing for less solar radiation. Nonetheless, the effect of these individual factors remains highly speculative and further research is needed to create more precise estimates of both the climatic factors as well as the contribution of a RB surface to $V R_{\text {total }}$.

Stalls 1 and 6, which were built with PICP surface layer but different sub-base materials, resulted in a $V R_{\text {total }}$ of $3 \%$ for CGA and $6 \%$ for CSA, and Stalls 4 and 5, both built with RB surface layer but with different sub-bases, resulted in a $V R_{\text {total }}$ of $25 \%$ for RCA and $10 \%$ for CSA. Differences in $V R_{\text {total }}$ within each of the two pairs of stalls can be attributed to the specific sub-base properties since all other variables are the same, though under the influence of the specific surface layer. Results indicate no marked difference for CGA and CSA when surfaced with a concrete gray PICP with SIR within the range of 400-900 mm/h, while difference in RCA and CSA when surfaced with a light brown RB with high SIR within the range of $6000-19,000 \mathrm{~mm} / \mathrm{h}$ are pronounced. This difference in $V R_{\text {total }}$ between Stalls 4 and 5 suggests that difference in particle size in favor of smaller particles, combined with the hydroscopic properties of RCA, provide substantial additional $V R_{\text {total }}$. However, it is possible that high surface permeability of RB facilitates this process. Due to limited PP system combinations in this study, the specific relationship cannot be fully explored.

Results found in this study for Stalls 1 and 6 are almost identical to those tested by [10], in which $V R_{\text {total_}}$ was found to be $8 \%$ if only direct storm water was to infiltrate, while $V R_{\text {total }}$ for Stall 3 over the course of this study is five-fold greater than found in the former study. The greater $V R_{\text {total }}$ might relate to differences in local climate conditions, differences in pavement design, or specific asphalt mix, e.g., aggregate size and asphalt binder contents. PP systems tested by Göbel et al. [18] similar to Stalls 1 and 6 found slightly higher $V R_{\text {total }}$ than in this study, which is probably due to PP systems being fully exposed to solar radiation and tested only during warm months, thus allow for more water to evaporate.

\subsection{Event Volume Reduction ( $\left.V R_{\text {event }}\right)$ and Event Lag-Time ( $t_{\text {lag }}$ )}

A total of 70 individual storm events greater than $3 \mathrm{~mm}$ depth were identified, representing $473 \mathrm{~mm}$ of the total rainfall, none being snow events. Of these 70 events, 22 events were selected 
for individual analysis, since the discharge rate exceeded the base-flow cut-off rate. The individual events were distributed evenly throughout the monitoring period, except for January, which was characterized by a continuous number of large storm events, and February, which was dominated by many small storm events, both leaving no events for analysis. For 18 of the 22 events analyzed, the $24 \mathrm{~h}$ antecedent rain depth was less than $1 \mathrm{~mm}$; for four events it was less the $10 \mathrm{~mm}$. The most intense rainfall was a summer rainstorm with a rain depth of $15.4 \mathrm{~mm}$ in $5 \mathrm{~h}(3 \mathrm{~mm} / \mathrm{h})$, corresponding to a return period of $0.5-1$ year. The greatest rain depth was $19 \mathrm{~mm}$ and occurred in spring (29 March), corresponding to a return period of 1-2 years. Event depths varied from $3 \mathrm{~mm}$ to $19 \mathrm{~mm}$, and event durations from $01: 46 \mathrm{~h}$ to $10: 53 \mathrm{~h}$, indicating a variety of different rainfall characteristics included in the analysis. However, except the aforementioned three storms, all represent a return period $<0.5$ year. Precipitation, volume reduction $\left(V R_{\text {event }}\right)$ and lag-time $\left(t_{\text {lag }}\right)$ for single events are shown in Table 3, together with descriptive statistics. At Stall 4, accumulating cement in the submerged pump resulted in malfunction periods, and thus only 10 events were included in the analysis.

Table 3. Descriptive statistics for individual storm events included in the analysis of volume reduction $\left(V R_{\text {event }}\right)$ and lag-time $\left(t_{\text {lag }}\right)$ to the experimental stalls as well as storm duration and storm depth.

\begin{tabular}{ccccccccc}
\hline Experimen-tal stall & Hydraulic Properties & $\mathbf{N}$ & Minimum & Median & Maximum & Mean & STD & CV \\
\hline \multirow{2}{*}{ Stall 1 } & $V R_{\text {event }}$ & 22 & $-6 \%$ & $30 \%$ & $71 \%$ & $31 \%$ & $23 \%$ & 0.75 \\
& $t_{\text {lag }}$ & 22 & $00: 20: 00$ & $02: 19: 30$ & $04: 39: 00$ & $02: 18: 14$ & $01: 02: 53$ & 0.45 \\
\hline \multirow{2}{*}{ Stall 2 } & $V R_{\text {event }}$ & 22 & $-9 \%$ & $40 \%$ & $85 \%$ & $44 \%$ & $25 \%$ & 0.58 \\
& $t_{\text {lag }}$ & 22 & $00: 16: 00$ & $01: 30: 00$ & $05: 00: 00$ & $01: 41: 03$ & $01: 06: 28$ & 0.66 \\
\hline \multirow{2}{*}{ Stall 3 } & $V R_{\text {event }}$ & 20 & $44 \%$ & $69 \%$ & $94 \%$ & $70 \%$ & $15 \%$ & 0.21 \\
& $t_{\text {lag }}$ & 20 & $00: 06: 00$ & $01: 00: 00$ & $06: 36: 00$ & $01: 27: 36$ & $01: 30: 24$ & 1.03 \\
\hline \multirow{2}{*}{ Stall 4 } & $V R_{\text {event }}$ & 10 & $20 \%$ & $46 \%$ & $95 \%$ & $56 \%$ & $25 \%$ & 0.41 \\
& $t_{\text {lag }}$ & 10 & $00: 51: 00$ & $03: 16: 30$ & $05: 25: 00$ & $03: 15: 54$ & $01: 19: 36$ & 0.41 \\
\hline \multirow{2}{*}{ Stall 5 } & $V R_{\text {event }}$ & 22 & $1 \%$ & $31 \%$ & $68 \%$ & $36 \%$ & $21 \%$ & 0.56 \\
& $t_{\text {lag }}$ & 22 & $00: 08: 00$ & $00: 39: 30$ & $03: 36: 00$ & $00: 59: 00$ & $00: 47: 54$ & 0.81 \\
\hline \multirow{2}{*}{ Stall 6 } & $V R_{\text {event }}$ & 22 & $1 \%$ & $27 \%$ & $68 \%$ & $30 \%$ & $19 \%$ \\
& $t_{\text {lag }}$ & 22 & $00: 05: 00$ & $01: 06: 30$ & $04: 02: 00$ & $01: 12: 27$ & $00: 49: 33$ & 0.68 \\
\hline \multirow{2}{*}{ Precipi-tation } & $\mathrm{D}^{1}$ & 22 & $01: 46: 00$ & $04: 43: 00$ & $10: 53: 00$ & $05: 19: 19$ & $02: 21: 22$ & 0.44 \\
\cline { 2 - 7 } & Sd & 22 & 3.0 & 5.4 & 19.0 & 7.0 & 4.1 \\
\hline
\end{tabular}

Table 3 and Figure 4 display mean $V R_{\text {event }}$ for each stall that ranged from $30 \%$ to $70 \%$, with a mean value of $42.7 \%$ and median of $33.8 \%$ over the cause of all stalls. Stall 3 returned the highest $V R_{\text {event }}$ of $70 \%$, ranging from $44 \%$ to $94 \%$, and Stall 6 the lowest with $V R_{\text {event }}$ of $30 \%$, ranging from $1 \%$ to $60 \%$. Results from $V R_{\text {event }}$ are greater than $V_{\text {total }}$, but with the same relative differences among stalls. Considerable variation between single events was observed, but a clear relationship between rain depth, intensity or duration and parameters tested for could not be established, although regression lines indicate that rain depths $<3.6 \mathrm{~mm}\left(R^{2}=0.78\right)$ did not result in discharge (above base flow of $0.3 \mathrm{~mm} / \mathrm{h})$ from Stall 4 and $<1.2-2.2 \mathrm{~mm}\left(R^{2}=0.83-0.94\right)$ from Stalls $1,2,3,5$ and 6 . Variation in $V R_{\text {event }}$ within each stall as well as among stalls is illustrated in Figure 5.

The $V R_{\text {event }}$ found in this study varied from the 53-63\% (equivalent to 34-37\% discharge) observed by $[12,13]$ testing PP surfaces similar to Stalls 1 and 6, although they used other product type and different sub-base aggregates. Furthermore, Pratt et al. [12] found no discharge from rainfall with a depth less than $5 \mathrm{~mm}$, which is higher than found at the current test site, and could be a result of the use of a geotextile in [12], whereas Brown and Borst [10] found an average of $1.37 \mathrm{~mm}$, spanning 0.87-1.81 $\mathrm{mm}$ across more sections of three types of PP systems, which is in agreement with what was found at similar PP systems at Stalls 1, 3, and 5. 


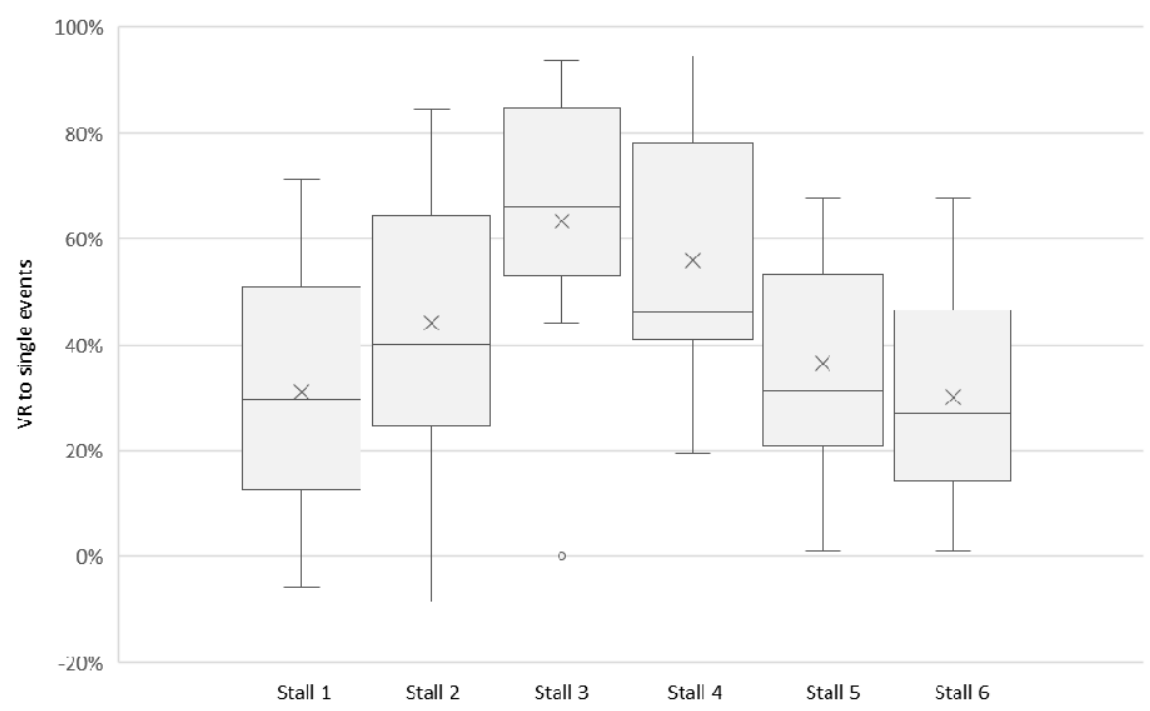

Figure 5. Variation in $V R_{\text {event }}$ to experimental stalls 1-6 displayed by quantiles, minimum and maximum values and outliers as a box-and-whisker plot.

Table 3 and Figure 6 display the median value for event lag-time, $t_{\text {lag, }}$, which was 1:38 $\mathrm{h}$ ranging from 0:39 $\mathrm{h}$ (Stall 5) to 3:16 $\mathrm{h}$ (Stall 4). Stalls 1, 2, 3, 5 and 6 were all within the range of 0:39-2:19 $\mathrm{h}$, thus displaying relatively homogeneous lag-times. Comparison across stalls with same PP sub-base but different PP surface (Stalls 1 and 6 and Stalls 1, 2 and 3) shows that lag-times are similar within each of the two sub-bases, thus indicating that regarding lag-time the properties of the sub-base override differences in PP surface properties, e.g., surface permeability. This also explains the considerable difference in lag-times for Stalls 4 and 5 (same PP surface, but different sub-base).

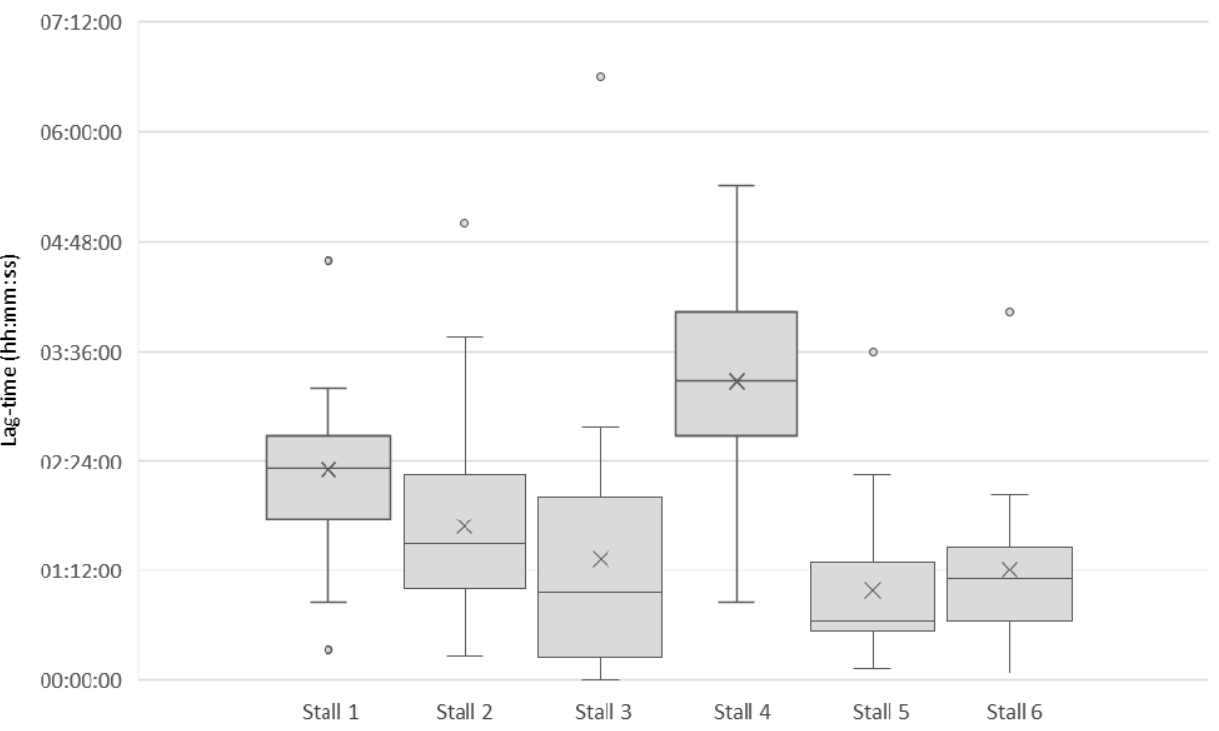

Figure 6. Variation in $t_{\text {lag }}$ to experimental stalls 1-6 displayed by quantiles, minimum and maximum values and outliers as a box-and-whisker plot.

The variation found within each stall is comparable to Abbott et al. [14] which documented lag-time varying from 0:05 $\mathrm{h}$ to 2:00 $\mathrm{h}$. For Stall 3, mean lag-time is lower than for unmaintained PA $(1: 52 \mathrm{~h})$ as well as maintained PA (3:16 h) tested by Pratt et al. [12], however the less coarse sub-base aggregates used in this study might explain the lower lag-time along with differences in asphalt mix as discussed in the former. Lag-times found in this study are considerable, and if PP systems that were 
to be up-scaled to cover greater parts of the city that would otherwise be covered with conventional (permeable) pavement, lag-time in combination with event-based volume reductions would most likely have the potential to reduce downstream peak-flows. However, if the effect of PP systems at a city-scale, e.g., by use of hydraulic modeling software, is to be quantified, it is crucial to include data from critical storms that was not included in this study and such studies should include analysis of peak-flow reductions as well.

\section{Conclusions}

Over the course of 12 months, we investigated the hydraulic properties of lined PP systems, that is, when built with a liner to prevent on-site infiltration, in a real-life setting connected with an underdrain to an existing sewer network. We measured storage capacity of three different base aggregates to be within the range of $27.5-35.3 \%$, when moist, in the order: gap-graded crushed stone > coarse-graded gravel $>$ recycled concrete aggregates. Lower storage capacity for moist aggregates than for dry was observed, particularly for recycled concrete aggregates that had hydroscopic properties as well as many small-size particles. Total volume reductions over the course of 12 months ranged from almost none $(3 \%)$ to more than $1 / 3(37 \%)$, pointing to substantial evaporation losses of some PP systems. Highest losses were observed for porous asphalt $(37 \%)$ and porous concrete paver $(16 \%)$, both having low surface infiltration rates and placed on course-graded gravel, and for resin-bound porous pavement over recycled concrete aggregates. Pairwise comparison indicated that volume reduction was highly influenced by surface properties such as surface permeability and surface color in the order (from highest reduction): porous asphalt $>$ porous concrete pavers $>$ permeable interlocking concrete pavers when overlaid coarse-graded gravel. Moreover, results indicate that properties of sub-base aggregates also affect total volume reduction, at least if the PP system surface provides high surface permeability. For permeable interlocking concrete pavement that allows infiltration through joints and placed on a subbase of crushed gravel or stone, the total volume reductions were inconsequential (3-6\%). Total volume reductions are ascribed to evaporation, and the marked differences observed call for further investigation of combinations of surface and subbase materials.

Analysis of 22 single rainfall events showed mean volume reductions ranging from $27 \%$ to $69 \%$, following the same order as total volume reductions, but being higher due to both some periods with continuous rain not being included and due to exclusion of discharge below a cut-off base-flow level. Median lag-time of the 22 events ranged from $00: 39 \mathrm{~h}$ to $03: 16 \mathrm{~h}$, pointing to a significant lag-time in all events and a significant range. Since none of the observed events represented the longer return periods used for drainage system dimensioning, e.g., the 5- or 10-year storms, the results for event volume reductions and lag-time cannot be directly related to the impact of lined PP systems on sizing of urban drainage systems. Nevertheless, with those limitations, the results show that all PP systems tested had the ability to alleviate storm water runoff by changing around half the precipitation to subsurface discharge at a base flow level of $0.3 \mathrm{~mm} / \mathrm{h}$ or less. The considerable difference in hydraulic performance to the individual PP systems tested in this study suggest that favoring one hydraulic property might be at the expense of others, which emphasizes the importance of addressing the context-specific hydraulic needs prior to the selection of PP system components.

Author Contributions: Jan Støvring, Torben Dam and Marina Bergen Jensen conceived and designed the experiments; Jan Støvring and Marina Jensen performed the experiments; Jan Støvring analyzed the data; and Jan Støvring, Torben Dam and Marina Bergen Jensen wrote the paper.

Acknowledgments: The authors want to thank the following organizations for financial support, technical advice and assistance in test sites construction: NCC, IBF, Midtgaard Granit \& Betonvarer, Byggros, Norrecco, Stenrand Grusgrav, MJK, Nyrup Plast, Rambøll, Copenhagen Municipality and HOFOR (Greater Copenhagen Utility).

Conflicts of Interest: The founding sponsors had no role in the design of the study; in the collection, analyses, or interpretation of data; in the writing of the manuscript, and in the decision to publish the results. The authors declare no conflict of interest. 


\section{References}

1. Woods-Ballard, B.; Kellagher, R.; Martin, P.; Jefferies, C.; Bray, R.; Shaffer, P. The SUDS Manual; Ciria: London, UK, 2007.

2. US EPA, OW. What Is Green Infrastructure? Overviews and Factsheets. US EPA, 30 September 2015. Available online: https://www.epa.gov/green-infrastructure/what-green-infrastructure (assessed on 22 December 2017).

3. Brattebo, B.O.; Booth, D.B. Long-Term Stormwater Quantity and Quality Performance of Permeable Pavement Systems. Water Res. 2003, 37, 4369-4376. [CrossRef]

4. Collins, K.A.; Hunt, W.F.; Hathaway, J.M. Hydrologic Comparison of Four Types of Permeable Pavement and Standard Asphalt in Eastern North Carolina. J. Hydrol. Eng. 2008, 13, 1146-1157. [CrossRef]

5. Scholz, M.; Grabowiecki, P. Review of permeable pavement systems. Build. Environ. 2007, 42, 3830-3836. [CrossRef]

6. Booth, D.B.; Leavitt, J. Field evaluation of permeable pavement systems for improved stormwater management. J. Am. Plan. Assoc. 1999, 65, 314-325. [CrossRef]

7. Drake, J.A. Performance and Operation of Partial Infiltration Permeable Pavement Systems in Ontario Climate. Ph.D. Thesis, The University of Guelph, Guelph, ON, Canada, 2013.

8. Drake, J.A.; Bradford, A.; Marsalek, J. Review of environmental performance of permeable pavement systems: state of the knowledge. Water Qual. Res. J. Can. 2013, 48, 203-222. [CrossRef]

9. Pezzaniti, D.; Beecham, S.; Kandasamy, J. Influence of clogging on the effective life of permeable pavements. In Proceedings of the Institution of Civil Engineers-Water Management; Thomas Telford Ltd: London, UK, 2009; pp. 211-220.

10. Brown, R.A.; Borst, M. Quantifying Evaporation in a Permeable Pavement System. Hydrol. Process. 2015, 29, 2100-2111. [CrossRef]

11. Knappenberger, T.; Jayakaran, A.D.; Stark, J.D.; Hinman, C.H. Monitoring Porous Asphalt Stormwater Infiltration and Outflow. J. Irrig. Drain. Eng. 2017, 143, 04017027. [CrossRef]

12. Pratt, C.J.; Mantle, J.D.G.; Schofield, P.A. Urban stormwater reduction and quality improvement through the use of permeable pavements. Water Sci. Technol. 1989, 21, 769-778.

13. Pratt, C.J.; Mantle, J.D.G.; Schofield, P.A. UK research into the performance of permeable pavement, reservoir structures in controlling stormwater discharge quantity and quality. Water Sci. Technol. 1995, 32, 63-69.

14. Abbott, C.L.; Comino-Mateos, L. In-Situ Hydraulic Performance of a Permeable Pavement Sustainable Urban Drainage System. Water Environ. J. 2003, 17, 187-190. [CrossRef]

15. Shergold, F.A. The test for the apparent specific gravity and absorption of coarse aggregate. J. Appl. Chem. 1953, 3, 110-117. [CrossRef]

16. Ferguson, B.K. Porous Pavements, Integrative Studies in Water Management and Land Development; CRC Press: Boca Raton, FL, USA, 2005.

17. Park, D.-G.; Sandoval, N.; Lin, W.; Kim, H.; Cho, Y.-H. A case study: Evaluation of water storage capacity in permeable block pavement. KSCE. J. Civ. Eng. 2014, 18, 514-520. [CrossRef]

18. Göbel, P.; Starke, P.; Voss, A.; Coldewey, W. Field Measurements of Evapotranspiration Rates on Seven Pervious Concrete Pavement Systems; NOVATECH: Lyon, France, 2013.

19. Hillel, D. Environmental Soil Physics: Fundamentals, Applications, and Environmental Considerations; Academic Press: San Diego, CA, USA, 1998.

20. Li, H.; Harvey, J.; Ge, Z. Experimental Investigation on Evaporation Rate for Enhancing Evaporative Cooling Effect of Permeable Pavement Materials. Constr. Build. Mater. 2014, 65, 367-375. [CrossRef]

21. Jorge, R.-H.; Andrés-Valeri, V.C.; Ascorbe-Salcedo, A.; Castro-Fresno, D. Laboratory Study on the Stormwater Retention and Runoff Attenuation Capacity of Four Permeable Pavements. J. Environ. Eng. 2016, 142, 04015068. [CrossRef]

22. Boogaard, F.; Lucke, T.; Beecham, S. Effect of age of permeable pavements on their infiltration function. CLEAN-Soil Air Water 2014, 42, 146-152. [CrossRef]

23. Støvring, J.; Dam, T.; Jensen, M.B. Surface sedimentation processes at permeable pavement systems: Implications for planning and design. Urban Water J. 2018, 15, 124-131. [CrossRef] 
24. American Society for Testing and Materials (ASTM). Standard Test Method for Surface Infiltration Rate of Permeable Unit Pavement Systems; (No. C1781/C1781M-13); American Society for Testing and Materials (ASTM): West Conshohocken, PA, USA, 2013.

25. Hood, M.J.; Clausen, J.C.; Warner, G.S. Comparison of Stormwater Lag Times for Low Impact and Traditional Residential Development. JAWRA J. Am. Water Resour. Assoc. 2007, 43, 1036-1046. [CrossRef]

26. Engelsen, C.J.; Wibetoe, G.; van der Sloot, H.A.; Lund, W.; Petkovic, G. Field site leaching from recycled concrete aggregates applied as sub-base material in road construction. Sci. Total Environ. 2012, 427, 86-97. [CrossRef] [PubMed]

27. Danish Meteorological Institute. Weather and Climate Data 2015 [in Danish: Vejr og Klimadata Årsoversigt 2015]. Available online: https://www.dmi.dk/vejr/arkiver/maanedsaesonaar/vejret-i-danmark-aaret2015/ (accessed on 28 November 2017).

28. Ladekarl, U.L.; Rasmussen, K.R.; Christensen, S.; Jensen, K.H.; Hansen, B. Groundwater Recharge and Evapotranspiration for Two Natural Ecosystems Covered with Oak and Heather. J. Hydrol. 2005, 300, 76-99. [CrossRef]

(C) 2018 by the authors. Licensee MDPI, Basel, Switzerland. This article is an open access article distributed under the terms and conditions of the Creative Commons Attribution (CC BY) license (http:// creativecommons.org/licenses/by/4.0/). 